\title{
POLYPHENOL OXIDASE-MEDIATED RESISTANCE TO COMMON CUTWORM
}

\author{
P. THIPYAPONG ${ }^{1}$, S. KLAKANKHAI ${ }^{1}$, M.J. STOUT ${ }^{2}$ \\ and J. ATTAJARUSIT ${ }^{1}$ \\ ${ }^{1}$ Suranaree University of Technology, Nakhon Ratchasima 30000, Thailand \\ ${ }^{2}$ Louisiana State University, Baton Rouge LA 70803, USA \\ Corresponding author: piyada@sut.ac.th
}

\begin{abstract}
Polyphenol oxidases (PPOs), catalysing the oxidation of phenolics to quinones, have been shown to confer resistance to Pseudomonas syringae and to lepidopteran insects including common cutworm (Spodoptera litura (F.)), beet armyworm (Spodoptera exigua (Hübner)) and cotton bollworm (Helicoverpa armigera (Hübner)). Transgenic tomato (Lycopersicon esculentum Mill.) plants constitutively expressing a sense PPO construct (OP) exhibited 5.3 to 5.7-fold higher PPO activity levels whereas the antisense PPO transgenic plants (SP) exhibited 2.1- to 2.4-fold lower PPO activity levels than nontransformed (NT) controls. Relative growth rates of the third instar were higher on the SP plants and lower on the NT and OP plants. In addition, efficiency of conversion of ingested food and efficiency of conversion of digested food of larvae feeding on OP leaves were up to 1.9 and 2.8 times lower than those of larvae feeding on NT and SP plants. PPO-mediated resistance was not associated with the antifeedant properties since larvae feeding on OP plants consumed relatively more than those feeding on NT plants. When common cutworm fed on leaflets at node 4 of tomato plants, PPO activity was locally induced, and PPO B and D were transcriptionally upregulated in leaf and stem tissues. These results substantiate the role of PPOs in insect resistance for integrated pest management programmes.
\end{abstract}

\section{LATEX IN DIFFERENT SWEETPOTATO (IPOMOEA BATATUS) VARIETIES AGAINST CYLAS FORMICARIUS INFESTATION}

\author{
W. WANTHANALERT and J. ATTAJARUSIT \\ Suranaree University of Technology, Nakhon Ratchasima, 3000, Thailand \\ Corresponding author: jutharat@sut.ac.th
}

Adults and larvae of sweet potato weevil, SPW (Cylas formicarius F.), destroy both tuber and vine of sweet potato (Ipomoea batatas L.) and cause serious yield loss at harvest and in storage. Latex is a possible defence mechanism against SPW infestation. A randomised complete block design with split split plots and 4 replicates was used. The main plots were nine sweet potato varieties, sub-plots were different ages $(1,2$, 3 and 4 months after planting) and sub-sub-plots were latex contents obtained from vine cuts at 10,20 and $30 \mathrm{~cm}$ above soil surface at which points the number of SPW wounds were observed and counted. The samples of fresh latex were weighed, dried at $60^{\circ} \mathrm{C}$ for $10 \mathrm{~h}$ and re-weighed. Latex contents were significantly different between the varieties at all ages and all heights. All varieties showed the highest latex content at the proximal end $(30 \mathrm{~cm})$ and decreased towards the basal ends. As sweet potato age increased, the latex content at each level decreased $(\mathrm{P}<0.01)$. The number of wounds was negatively correlated with both fresh and dried latex content weight $\left(r^{2}=-0.712\right.$ and -0.585 respectively, $\mathrm{P}<0.01$ ), indicating that when latex content was high, SPW infestation was low. This study showed that latex was one of the important resistance factors against SPW infestation. 